\title{
La Violencia en Colombia de M. Guzmán, O. Fals y E. Umaña y las trasgresiones al Frente Nacional ${ }^{1}$
}

\author{
Alberto Valencia Gutiérrez \\ Universidad del Valle, Colombia \\ alberto.valencia@correounivalle.edu.co
}

\begin{abstract}
Resumen
El artículo lleva a cabo una presentación del libro La Violencia en Colombia. Estudio de un proceso social en el marco de lo que representa su publicación en un momento en que el Frente Nacional, pacto bipartidista de alternación y de reparto del poder entre los partidos liberal y conservador, pretende hacer "borrón y cuenta nueva" de lo sucedido durante la llamada Violencia de los años 1950. El objetivo del artículo es dar cuenta de cómo la aparición de este libro, lo mismo que el juicio político que se llevó a cabo en el Senado en contra del general Rojas Pinilla, constituye una verdadera transgresión de los presupuestos en los que se basaba el Frente Nacional.
\end{abstract}

Palabras clave: academia y política, Frente Nacional, juicios políticos, memoria colectiva, La Violencia en Colombia.

\section{La Violencia en Colombia by M. Guzmán, O. Fals y E. Umaña and the Transgression of the Frente Nacional}

\begin{abstract}
The article carries out a presentation of the book La Violencia en Colombia. Estudio de un proceso social, in the context of what its publication meant at a moment when the Frente Nacional, a bipartisan pact that established the alternation in and distribution of power between the Conservative and the Liberal parties, attempted to wipe the slate clean with respect to what occurred during the socalled Violence of the 1950s. The objective of the article is to discuss how the publication of the book, together with the political trial held in the Senate against General Rojas Pinilla, constituted a transgression of the assumptions grounding the Frente Nacional.
\end{abstract}

Keywords: academy and politics, Frente Nacional, political trials, collective memory, Violence in Colombia.

1 Artículo publicado en la Revista Colombiana de Sociología, Volumen 35, número 2, julio-diciembre de 2012, pp. 15-33. Agradecemos al autor y al editor de la revista la autorización para incluir este artículo en nuestro dossier. 


\section{Introducción}

La Violencia en Colombia. Estudio de un proceso social, el primer gran estudio de corte académico sobre lo sucedido durante el periodo llamado La Violencia de los años 1950. La aparición de la primera edición de este libro en junio de 1962, pocas semanas antes de que terminara el primer gobierno del Frente Nacional en cabeza de Alberto Lleras Camargo, constituye un acontecimiento político de primera magnitud en su momento, por el hecho de que habla de un tema del que nadie quería hablar y de una época que se quería borrar del imaginario político de los colombianos. El libro, dadas las revelaciones que ofrece sobre lo sucedido, representa, sin lugar a dudas, una trasgresión de varios de los principales presupuestos de este pacto político. No en vano su publicación suscita un gran escándalo nacional en la prensa, el Congreso y los sectores políticos más diversos.

El objetivo de este artículo es mostrar el contraste entre la manera como el Frente Nacional pretendió construir representaciones de lo sucedido en los años anteriores y las tesis presentadas por el libro que contradicen dichas representaciones. De esta manera, queremos contribuir a la construcción del problema de la memoria colectiva de los años cincuenta.

\section{El libro y el Frente Nacional}

El Frente Nacional es la estrategia política ideada por los principales dirigentes colombianos, conservadores y liberales, de los años cincuenta para poner fin a los enfrentamientos bipartidistas que habían caracterizado la historia nacional y que habían encontrado, durante los doce años anteriores, una agudización extrema en lo que se conoce como La Violencia que había asolado al país y había dejado un saldo no inferior a los 200.000 muertos hasta 1962, según los cálculos que aparecen en el propio libro y que son corroborados años después (Guzmán, Fals y Umaña, 1980, pp. 287-293; Oquist, 1978, pp. 57-97).
El Frente Nacional partió del diagnóstico de que La Violencia era consecuencia del interés de los partidos políticos por perpetuarse en el poder. La historia colombiana, desde la creación de los partidos a mediados del siglo XIX, puede describirse como una sucesión de hegemonías de partido, que en muchos casos se acompaña de hechos violentos para conquistar el poder o para conservarlo. Durante el siglo XIX, pueden contarse al menos siete guerras civiles en nombre de los partidos; hasta la llamada Guerra de los Mil Días (1899-1902), que dejó un saldo aproximado de 100.000 muertos. En el momento en que se instaura la llamada República Liberal, en 1930, se produce un brote de violencia partidista en los departamentos de Santander y Boyacá, orientado a cambiar la composición conservadora del electorado por una mayoría liberal, que deja cerca de 10.000 muertos (Guerrero, 1991). Este acontecimiento se puede considerar como una especie de "eslabón perdido" entre las guerras civiles y La Violencia.

El dirigente liberal Alberto Lleras Camargo, uno de los principales impulsores del acuerdo junto al líder conservador Laureano Gómez, define el Frente Nacional en los términos siguientes: "la experiencia, dura, sangrienta y prolongada, nos ha enseñado que si cualquiera de los dos partidos pretende excluir al otro radicalmente del manejo de la cosa pública [...], la violencia crece como un hongo fatídico". Y, por consiguiente, la solución propuesta consiste en:

Un gobierno de los dos partidos, ejecutado a nombre de los dos, con su responsabilidad conjunta, y apoyado por una fuerza política [...] para que lo defienda y lo mantenga, le asegure el respaldo de la opinión ciudadana y lo haga inmune al sectarismo. (Zalamea, 1957, p. 57)

Esta fórmula constituye para Lleras "la cura inmediata de esta situación de crisis" ${ }^{\prime 2}$.

2 "Palabras del director del Partido Liberal en la confirmación de la proclamación de la candidatura del señor Guillermo León Valencia, en Bogotá, el 12 de abril de 1957" (Zalamea, 1957, p. 57). 
Sobre la base de este diagnóstico, se establece un pacto de paridad en la administración pública y de alternación en la presidencia de la República a partir del año 1958. La alternación se pactó inicialmente a doce años pero, en 1959, el Congreso la extendió a dieciséis. La reforma constitucional de 1968 postergó la paridad hasta 1978, cuatro años más después de terminado el último gobierno compartido $\mathrm{y}$, a partir de esa fecha y de manera indefinida, estableció la llamada participación "adecuada y equitativa" del partido perdedor en el gobierno. Así, el pacto del Frente Nacional se termina realmente con la Reforma Constitucional de 1991, que deroga el artículo 120 de la Constitución Nacional, el último rezago del acuerdo bipartidista.

El ambiente político en que se inaugura el Frente Nacional se caracteriza por el hecho de que todos los partidos y todas las vertientes, con muy pocas excepciones, giran alrededor del universo político definido por el Frente Nacional. La prensa nacional se declara en términos generales favorable al pacto, al que considera como la única alternativa viable en ese momento. El Espectador habla de una nueva esperanza para Colombia y la única solución posible para los problemas nacionales. El Colombiano lo considera un movimiento insustituible para el país. El Tiempo propone que se hable de una "segunda República", a la manera francesa, ya que la tradición republicana de Colombia se había interrumpido por una guerra civil (El Tiempo, 1958, 1ro de septiembre, Editorial). El lenguaje que predomina en la prensa es de concordia y de entendimiento. El Frente Nacional es considerado como la única manera de desterrar la dictadura, de acabar con el odio, la violencia y el resentimiento, y de "arreglar cuentas con el cruento pasado". Para El Tiempo es "un cordial evangelio civilizador de la convivencia" (El Tiempo, 1959, 2 de enero, Editorial).

No obstante, el Frente Nacional no era simplemente un acuerdo político hacia el futuro, sino un acto de amnistía implícita hacia el pasado inmediato en el que habían estado comprometidos, unos más otros menos, los principales dirigentes políticos del país. El acuerdo no estableció ningún tipo de proceso de responsabilidades con respecto a lo sucedido e, incluso, las formas de reparación de las víctimas fueron bastante precarias; en otros términos, fue un manto institucional de impunidad y una carta blanca para que los responsables de La Violencia se reintegren a la vida política nacional sin ningún contratiempo. De hecho, durante los años de vigencia del pacto, nos encontramos con nombres muy conocidos en los años de La Violencia que se presentan como candidatos presidenciales o asumen altos cargos en el gobierno (ministros, alcaldes, funcionarios).

Al revisar la prensa de la época, llama la atención el ambiente de absoluta impunidad que la inmensa mayoría de las élites políticas del momento avalan y ratifican. La idea de los principales líderes políticos es que, antes dequese reanude la controversia partidista y la libre lucha democrática por el poder, exista una especie de interregno de reconstrucción institucional bajo el signo del perdón y el olvido que garantice un ambiente de civilización y de concordia. Según Lleras Restrepo, un presupuesto fundamental del pacto del Frente Nacional es que se cancele "toda recriminación por el pasado" y se renuncie a "enfrentar de nuevo a los partidos" sobre la responsabilidad de lo sucedido porque de otra manera "la concordia no se podría alcanzar". El liberalismo, de la mano de uno de sus principales dirigentes, renuncia voluntariamente a que lo "arrastren en un confuso proceso histórico" de responsabilidades (El Tiempo, 1959, 8 de febrero, pp. 1 y 10).

La gran prensa hace eco a este ambiente de impunidad. Según el periódico El Tiempo en "el olvido de todos nuestros dolores, de todos nuestros sufrimientos, afrentas y odio" está la clave de la convivencia. Hurgar "las oscuras raíces" y buscar "tendenciosamente orígenes y responsabilidades" es "una manera de envenenarnos y mantenernos en estado de prevención y de cólera. La reminiscencia de los rencores y resentimientos solo conduce al caos y 'al estímulo oscuro de las pasiones' y así "es imposible moralmente rehacer a la nación" ( $E l$ Tiempo, 1959, 7 de febrero, Editorial). El Crisol de Cali reconoce toda "la amargura de esas 
épocas de vergüenza y de oprobio" y todo lo que fue el "sufrimiento del liberalismo", pero considera que "no se gana nada con resucitar en la mente del pueblo esos recuerdos" ya que "las viudas y los huérfanos no van a rescatar por este motivo a sus seres queridos" (1958, 31 de enero, Editorial). Los periódicos conservadores se unen a esta unanimidad con respecto al clima de impunidad frente al pasado, con algunas pequeños matices en el caso de los periódicos de orientación ospinista, que mantienen viva la acusación contra Laureano Gómez por la guerra que hace contra ellos, mientras "hace la paz con los liberales".

La renuncia a un juicio de responsabilidades sobre lo sucedido, paradójicamente, se acompaña en los periódicos de la época con una serie de sermones contra la impunidad, a la que se considera como "la causa de muchos de los problemas nacionales". La República afirma que el principal propósito del gobierno de Lleras Camargo es evitar la impunidad, porque es uno de los motivos del grave mal que nos aqueja y nos arrastra hacia el abismo (La República, 1958, 8 de agosto, Editorial). El Crisol de Cali dice que "las experiencias dolorosas que los colombianos han vivido durante los últimos lustros son el resultado de la impunidad" y que la primera necesidad en este momento de desarrollo del Frente Nacional es la justicia (El Crisol, 1959, 6 de febrero, Editorial). Sin embargo, cuando se dice que hay que hacer justicia, se piensa fundamentalmente en el juzgamiento a Rojas Pinilla y de alguna manera a los grandes responsables de la época de La Violencia.

El pacto político del Frente Nacional fue trasgredido en sus comienzos en dos oportunidades. La primera, proveniente de las propias élites políticas, fue el juicio político que se le siguió a Rojas Pinilla en el Congreso de la República entre agosto de 1958 y abril de 1959. La segunda, bajo la iniciativa del sector académico representado por la Facultad de Sociología de la Universidad Nacional de Colombia, fue la publicación del libro La Violencia en Colombia en 1962.

\section{La primera trasgresión del pacto político}

Rojas Pinilla abandona el poder el 10 de mayo de 1957 en favor de una Junta Militar de gobierno que supuestamente iba a guardarlo lealmente en manos de las Fuerzas Armadas. Sin embargo, esta Junta rápidamente se pliega a las exigencias de las élites políticas liberales y conservadoras impulsoras del Frente Nacionaly, 15 días después de la salida del General, nombra a la Comisión Nacional de Instrucción Criminal, que debía investigar los malos manejos de los funcionarios públicos durante "los últimos tiempos", pero que termina limitándose a investigar lo sucedido durante el gobierno de Rojas. Ante la inminencia de su regreso, durante el primer semestre de 1958 y en vísperas de la inauguración del primer gobierno del Frente Nacional, las élites políticas construyen sobre la marcha, con base en los informes de dicha comisión, una serie de cargos contra el expresidente, para ser tramitados, como lo establece la Constitución, en el Congreso Nacional (Valencia, 2012).

Durante el segundo semestre de 1958 se llevan a cabo los principales trámites procesales para el juzgamiento de Rojas en la Cámara de Representantes y en el Senado. La idea de los promotores del juicio es terminar lo más pronto posible con este proceso, pero las prácticas dilatorias de la defensa lo alargan cada vez más, hasta el punto de que el presidente Lleras, en clara violación de la Constitución, se ve obligado a llamar a sesiones extraordinarias al Congreso en enero de 1959 para que concluya el trabajo iniciado ${ }^{3}$.

Los cargos iniciales que se establecen contra Rojas Pinilla son relativamente secundarios

3 El presidente de la República no podía llamar al Congreso a sesiones extraordinarias para que se ocupara de un asunto como el juzgamiento a un alto funcionario, ya que esto de su propia competencia y no de la del Presidente. 
con respecto a los graves problemas que se habían presentado durante su gobierno y fueron construidos de tal manera que solo comprometieran al General y dejaran por fuera la responsabilidad de otros funcionarios de su gobierno o de las administraciones anteriores, como las de Laureano Gómez y Ospina Pérez. Sin embargo, el alargamiento del proceso y el protagonismo de la gran prensa en la promoción de la ruina política del General, entre otros aspectos, hace que el caso se salga de las manos de sus impulsores y que comience a producir "efectos imprevistos". Por eso, cuando comienzan las sesiones del Senado el 22 de enero de 1959, la situación se desborda. A partir de ese momento ya no se trata simplemente de juzgar a Rojas por una serie de cargos puntuales, sino de pasar revista a los principales acontecimientos de la historia contemporánea reciente y de llevar a cabo un juicio de responsabilidades de La Violencia de los años cincuenta.

El periódico La República reconoció, en este sentido, que con el avance de las audiencias "se acumulan los más disparatados elementos de la controversia y falta muy poco para que la totalidad de la historia contemporánea [fuera] puesta en tela de juicio". Y considera que el "fiscal de la causa", es decir, el Congreso de la República, "debe poner límites y fronteras" porque bien parece que "los límites del juicio son los de la historia nacional" (La República, 1959, 1.ro de febrero, Editorial). Cada uno de los acontecimientos de la época o algunos de sus principales protagonistas son sometidos a discusión: la personalidad de Laureano Gómez y de Rojas Pinilla, el 13 de junio de 1953, la legitimidad del gobierno de Rojas, los sucesos del 10 de mayo de 1957, las actuaciones de la Junta Militar, la legitimidad del Frente Nacional, entre muchos otros.

El juicio de responsabilidades a La Violencia no fue previsto por sus promotores, pero ante la ampliación de los temas tratados se volvió inevitable. El primer cuestionamiento a lo sucedido durante esos años tiene que ver con la responsabilidad de la muerte de Jorge Eliécer Gaitán. El general Rojas Pinilla había prometido al comienzo del proceso que revelaría el nombre de los autores intelectuales del magnicidio y de esta manera introdujo en el juicio el "fantasma de Gaitán", que a partir de ese momento estaría presente hasta el final. La pregunta por los asesinos intelectuales es, al mismo tiempo, una pregunta por los orígenes de La Violencia, en la medida en que en la opinión circula la idea de que el 9 de Abril, aun en contra de las evidencias que muestran lo contrario, había representado su comienzo ${ }^{4}$.

El segundo cuestionamiento proviene de los partidarios de Rojas en la Cámara de representantes, en cabeza de José María Nieto Rojas, que señalan a los liberales como responsables de La Violencia, para ello, toman como paradigma lo sucedido en los Llanos Orientales. El tercer cuestionamiento proviene de los defensores de Rojas, que hacen recaer toda la responsabilidad en Laureano Gómez y en su hijo, Álvaro. El cuarto cuestionamiento proviene de los acusadores, quienes excusan de cualquier tipo de culpa a los partidos políticos y la reorientan hacia Rojas Pinilla. Finalmente, el quinto cuestionamiento proviene del propio Rojas, quien se exime de toda responsabilidad y acusa a Laureano Gómez. En el marco de estas recriminaciones mutuas, los horrores de La Violencia se recuerdan y se reviven con lujo de detalles en las intervenciones de los protagonistas del juicio.

El pacto político del Frente Nacional exigía que cayera un manto de perdón y olvido sobre ciertos protagonistas de La Violencia, en especial sobre la figura de Laureano Gómez, quien había sido considerado uno de los principales responsables, pero que ahora, al convertirse en uno de los grandes baluartes de la nueva situación política, debía aparecer como un demócrata convencido,

4 La Violencia comienza realmente durante el segundo semestre de 1946, cuando se empiezan a presentar ataques conservadores contra los liberales en un afán de cambiar la composición del electorado con miras a las elecciones de 1947. Durante este último año hubo 14.000 víctimas. 
partidario de la paz y la convivencia. Bajo la iniciativa de los defensores de Rojas, la figura del líder conservador pasó a ser objeto de un escrutinio minucioso, que terminó por sacar a la luz una serie de hechos de violencia en los que se presume su participación. De esta manera, el debate del juicio hace que lo que tenía que ser olvidado y reprimido por conveniencia política, para garantizar el éxito del Frente Nacional, se convierta en objeto de debate público tanto en el Congreso como en la prensa (Senado de la República, tomo II, 1960).

Ante la acumulación de desbordamientos en las sesiones del Senado durante el juicio, sus promotores se ven en la obligación de darlo por terminado e impiden que Rojas Pinilla termine su defensa, lo que supone una grave violación de la ley penal que prohíbe cortar la palabra al acusado. Y así, el juicio se convierte en la plataforma política que hace posible revivir la figura de Rojas Pinilla y convertirlo en uno de los grandes caudillos populares de América Latina durante los años sesenta.

\section{La segunda trasgresión del pacto político}

La segunda trasgresión del pacto político fue la publicación, en 1962, del libro La Violencia en Colombia que, aunque tiene una base académica que sustenta sus hipótesis, apela también a la denuncia, introduce en la opinión pública nacional del momento una descripción de lo sucedido durante los años cincuenta, es decir, habla de lo que estaba prohibido hablar.

El Frente Nacional, en el marco de un lenguaje de la concordia y del entendimiento, había contribuido significativamente a borrar el pasado inmediato del imaginario político de los colombianos y a hacer ininteligible para las nuevas generaciones lo que había estado en juego durante La Violencia, con base en dos estrategias que el libro de Monseñor Guzmán et al. pone en cuestión.

La primera estrategia, construida con base en la influencia de la gran prensa, consiste en establecer una diferencia entre la barbarie, representada por la violencia anterior, y la civilización, representada por el propio Frente Nacional. El Tiempo considera que, antes del pacto político, el país estaba "al borde del abismo" y de la disolución definitiva, y que ahora se encuentra frente a la disyuntiva de civilizarse o perecer, es decir, "Frente Nacional o caos" (El Tiempo, 1959, 2 de enero, Editorial). El nuevo pacto político "logró frenar los destructores instintos, las desbordadas pasiones, contener el turbio río de la barbarie que amenazaba con anegar todo en cenizas y sangre" (El Tiempo, 1959, 7 de febrero, Editorial). El Espectador traduce la antinomia entre civilización y barbarie en términos de "Frente civil o guerra civil". El periódico El Crisol de Cali considera que resucitar los antiguos antagonismos políticos significaría "el retorno inmediato a la barbarie". Y la barbarie pertenece al reino de lo innombrable y de lo inefable, aquello de lo que no se puede hablar y de lo que no se puede discutir.

En este marco, el ambiente político del Frente Nacional es perfectamente compatible con la representación de La Violencia como una entidad colectiva, impersonal y anónima, equivalente a un cataclismo o a una catástrofe natural, que se abate por los campos y "siembra la destrucción a su paso", en la que no hay actores ni intereses claramente definidos y, por consiguiente, tampoco hay responsables. La Violencia así representada aparece como un mito por fuera del tiempo y del espacio, como una especie de entidad autónoma y suprahistórica que de cuando en cuando regresa y se instala en la vida política de los colombianos, a la manera de un "eterno retorno de lo mismo". Aún hoy en día, los campesinos colombianos hablan de La Violencia como aquel "ente colectivo" que les robó la cosecha, les quitó la propiedad, los sacó del campo y exterminó a sus amigos y parientes (Ortiz, 1987, pp. 37-44).

La segunda de las estrategias consiste en "sustituir una cosa por otra", en construir el efecto metonímico de reemplazar la parte por el todo y convertir una situación relativamente secundaria en el problema fundamental. Bajo la égida de la gran prensa, aquella época no se recuerda como el momento del enfrentamiento 
entre liberales y conservadores, cuando se cometían horribles crímenes en nombre de los partidos, sino como la época de la dictadura de Rojas Pinilla, que se convierte de esta manera en un "recuerdo encubridor" de La Violencia.

El libro La Violencia en Colombia pone en cuestión estos fundamentos del Frente Nacional en al menos tres aspectos. En primer lugar, va exactamente en contravía de la tendencia a tender un manto de silencio y de olvido sobre lo sucedido y de sacar por esta vía al fenómeno de la trama histórica. En segundo lugar, transforma el juicio de responsabilidades propuesto, tanto el que aparece en las versiones liberales y conservadoras como el que se presenta en la versión mítica, y lo ubica en otro plano, en el que las oligarquías de ambos partidos tienen plena responsabilidad. En tercer lugar, en contra de un sistema político que pretende negar la presencia de los sectores populares en la política, lleva a cabo una investigación sobre lo que es el campesino colombiano. En las líneas siguientes vamos a tratar de mostrar cada uno de estos tres aspectos.

\section{La inscripción del conflicto en la historia}

Los objetivos de los autores del libro $L a$ Violencia en Colombia son despertar del letargo a la opinión pública, modificar una actitud pasiva frente a lo sucedido, poner a discutir y a reflexionar a Colombia entera, aun asumiendo los insultos y las diatribas que sobre ellos podrían caer. $Y$ todo ello de tal manera que se pueda "desmontar la maquinaria del odio" y crear una "voluntad de actuar" para superar la situación y evitar que se repita. Según sus autores, el país carece de una "noción exacta de lo que fue La Violencia” (Guzmán, Fals y Umaña, 1980, p. 23), así que el libro busca contar claramente lo que ocurrió. El asunto consiste entonces en saber cómo lo cuentan.

Para resolver esta pregunta hay que tener en cuenta, en primer lugar, que el libro La Violencia en Colombia tiene al mismo tiempo dos perfiles que no necesariamente se excluyen. Por una parte, es un texto político, sin lugar a la menor duda, orientado a denunciar $\mathrm{y}$, por esta vía, a producir un efecto sobre sus lectores. De manera recurrente, Monseñor Guzmán interrumpe la secuencia de la narración para hacer preguntas con respecto a lo sucedido. Este es el caso, por ejemplo, del capítulo en el que describe las características de los crímenes cometidos. Allí, al tomar la voz de Orlando Fals Borda se pregunta si:

[...] ¿no sería masoquista rumiar los temas tremendos de la violencia política $[\ldots]$ repitiendo sus lúgubres detalles [...] sin alcanzar a levantar la vista para descubrir alguna luz, alguna esperanza de respiro o salvación?". Y responde que es "necesario descender con horror, con asco, pero con ilimitada comprensión humana [...] a ese subfondo de miseria [...] para buscar soluciones adecuadas con conocimiento minucioso de su tragedia y de su patología. (Guzmán, Fals y Umaña, 1980, p. 225)

Ningún sociólogo verdaderamente moderno encabezaría hoy en día un estudio de los crímenes con estas frases. Ese carácter político de este texto se articula con un carácter académico, como se puede verificar en el rigor de lo autores para establecer los hechos con precisión, para definir las cifras y la magnitud del conflicto, para comparar versiones diversas sobre un mismo suceso y, en general, por el afán que muestra en sustentar cualquier tipo de afirmación.

En síntesis, se podría afirmar que el libro es una especie de híbrido entre las dos orientaciones, política y académica, y en tal sentido no podría ser considerado como un texto adecuado ciento por ciento a las exigencias de una sociología moderna. No se puede negar su carácter académico, pero es un hecho que aún se encuentra atrapado en un estilo de denuncia política pura y simple. Para comprender las ideas que se quieren sustentar en este artículo, es importante tener en cuenta este doble carácter.

En contravía con la situación planteada por el Frente Nacional, el libro La Violencia en Colombia contribuye a hacer inteligible la época que se debía olvidar, pone a hablar a la barbarie, se preocupa por recuperar su sentido y, de esta manera, inscribe el fenómeno social violento de 
los años cincuenta en una trama histórica en la que hay actores e intereses en juego claramente delimitados, que responden a una temporalidad y a una geografía concretas.

En primer lugar, se elabora una periodización del conflicto para comprenderlo en cinco momentos: 1946-1949; 1949-1953; interregno de Rojas Pinilla en 1953 y 1954, 1954-1958; 1958 en adelante. Esta periodización sigue vigente en la mayoría de los investigadores. En segundo lugar, lleva a cabo una minuciosa construcción de la geografía de la violencia en cada una de las regiones escogidas y de acuerdo con los periodos definidos como "primera y segunda ola de violencia": Tolima región por región, municipio por municipio; los Llanos Orientales, Boyacá, Antioquia, Cundinamarca, Caldas, Santander, Cauca, Huila y otras regiones. Y todo ello acompañado por mapas que ya hacen parte del patrimonio fundamental de la investigación sobre el tema. El capítulo cuarto completa el cuadro con una descripción de las características de los departamentos afectados, el inventario de los municipios y de los jefes de los grupos.

Estos autores se ciñen a una forma de hacer sociología que, si parafraseamos una famosa expresión del sociólogo Robert Merton, podríamos denominar "sociología de alcance medio" ${ }^{5}$. En la segunda parte del libro, se lleva a cabo una descripción de la violencia en un terreno estrictamente social, intermedio entre los aspectos políticos de carácter nacional y las interpretaciones puramente económicas. Esto se contrapone con el tipo de literatura que se impone en los años posteriores a la publicación de este libro, en la cual se pretende reducir los enfrentamientos a los lugares abstractos de la estructura de un modo de producción, como aparece en el marxismo economicista y teleológico; o a la descripción del contexto político nacional, como aparece en la literatura de los llamados politólogos de los años sesenta y setenta. Nos encontramos aquí, por el contrario, "con una descripción empírica, específica y concreta de los actores de carne y hueso, de sus acciones y de sus organizaciones" (Valencia, 2012).

En la segunda parte del libro, que comprende los capítulos $\mathrm{V}$ al $\mathrm{X}$, Guzmán, con base en múltiples ilustraciones, nos muestra una serie de perfiles muy claros de quienes fueron los campesinos que hicieron la violencia: su procedencia, su edad, su nivel de escolaridad, su tipo étnico o racial, la religión que profesaban, sus ideas y mentalidades, el papel de la mujer y de los niños. Nos describe las características de las comunidades desplazadas y la manera como se forma un nuevo grupo y se esbozan nuevas instituciones en el marco de la persecución. Nos presenta igualmente las características de los grupos guerrilleros y de los comandos: las normas de convivencia que se establecían, las diferencias que existían entre ellos; las características de las cuadrillas y de sus jefes. Una sociología de este tipo difícilmente encuentra parangón en la literatura posterior sobre La Violencia.

El libro también presta atención especial a la manera cómo funcionan internamente los grupos en armas. Se revelan técnicas como el "boleteo" o los signos utilizados para establecer formas de comunicación; también aparecen las tácticas y las estrategias que ponen en práctica y la manera como actúan los protagonistas; las formas de financiación y de consecución de las dotaciones bélicas y de sus vestuarios; las insignias y los símbolos a través de los cuales se identifican. Especial mención merecen las "manifestaciones culturales de los grupos en conflicto", como es el caso del lenguaje que emplean: los apodos, las canciones y la música en general que crean al calor de la lucha; las coplas y los versos a través de los cuales dan razón de sus actos.

El capítulo IX marca una pauta fundamental frente a los estudios posteriores de La Violencia, debido a la descripción minuciosa que lleva a cabo de las múltiples formas de matar que se ponen en práctica en ese momento: picar

5 Merton habla de "teorías de alcance intermedio" (1995, pp. 56-91). 
para tamal, "bocachiquiar", "no dejar ni la semilla", corte de franela, corte de corbata, corte de mica, corte francés, corte de oreja, formas de descuartizamiento, posibles prácticas de antropofagia, empalamiento, crímenes sexuales, piromanía, genocidios, entre muchos otros.

Este tipo de descripciones pueden parecer superfluas e innecesarias para algunos, incluso, pueden ser consideradas como la expresión de una especie de "actitud mórbida" que pretende revivir sucesos dolorosos en lugar de olvidarlos. Sin embargo, el recorrido minucioso por este tipo de prácticas permite que se planteen varias preguntas fundamentales que la literatura escrita hasta el momento no ha logrado responder: ¿por qué los campesinos se matan como se matan? ¿Cómo es posible dar cuenta de los excesos de sevicia y de horror que se asocian a los enfrentamientos bipartidistas? De la descripción de Monseñor Guzmán se deduce que la manera de matar no es arbitraria ni hace parte propiamente de una especie de "herencia atávica" de unos pueblos primitivos, indígenas o salvajes, sino que es un componente fundamental del sentido de los acontecimientos.

\section{La redefinición del sentido de las responsabilidades}

La Violencia en Colombia también pone en cuestión los fundamentos políticos del Frente Nacional al establecer una redefinición radical del sentido de las responsabilidades, en contravía tanto de la desculpabilización generalizada implícita en la versión mítica que presenta a La Violencia como la irrupción de una barbarie en la que no hay actores concretos $\mathrm{y}$, por consiguiente, tampoco hay responsables, como del juego de recriminaciones mutuas que se establecen entre los partidos políticos.Desde este punto de vista, el libro, como primer documento serio de análisis de lo sucedido, constituye un hito de suma importancia en el proceso de elaboración de un relato legítimo de los acontecimientos y nos plantea muchas preguntas que hoy en día siguen vigentes.

El Frente Nacional, como reino de la civilización frente a la barbarie, para tratar de eximir de responsabilidades a los liberales y a los conservadores, había convertido el periodo de La Violencia en una especie de "punto muerto", vacío de significación en la trama de los acontecimientos. Dicha época era algo de lo que nadie quería hablar, algo en lo que nadie quería pensar y en lo que nadie podía encontrar las fuentes primordiales para la construcción de una identidad política. Los partidos políticos que tuvieron protagonismo en los años posteriores buscaron sus héroes y sus emblemas en otras épocas. Este olvido se manifiesta, por ejemplo, en el hecho de que ni siquiera actualmente existe un monumento que conmemore a las víctimas de este periodo.

Cada uno de los partidos pretendía "limpiarse" de la responsabilidad por lo sucedido con el artificio de endilgar a su adversario el origen de los enfrentamientos y de los horrores: los culpables fueron "los otros" y no "nosotros". Este tipo de representación aparece de manera especial en los panfletos y en los libracos escritos al calor de la lucha, como puede verse en la prensa sectaria de la época o en el juicio político que se hace contra Rojas Pinilla en el Congreso de la República, durante el cual se revive la situación en términos de un enfrentamiento primario entre los partidos, como hemos visto líneas atrás. La Violencia en Colombia no asume la posición política de ninguno de los grupos políticos comprometidos: liberales, conservadores o comunistas; la descripción que nos presenta Monseñor Guzmán es que ambos partidos comparten la responsabilidad de La Violencia.

El Partido Liberal, que con frecuencia es presentado simplemente como víctima de la acción de los conservadores, aparece en este libro igualmente comprometido en los enfrentamientos. En contra de la idea de que fueron los conservadores los que iniciaron la violencia con el cambio de régimen en 1946, Monseñor Guzmán sostiene que la violencia se origina a inicios de los años treinta, con la violencia ejercida por los liberales contra los conservadores, como consecuencia del cambio de hegemonía partidista. Los conservadores, desde esta perspectiva, no estarían haciendo otra 
cosa que respondiendo, doce años más tarde, a la agresión liberal.

El Partido Liberal fue reaccionando poco a poco a la provocación de los conservadores, sobre todo a partir de 1949, y sus actos de respuesta no se limitaron simplemente a ser una estrategia defensiva. La barbarie fue recíproca: los horrores y las atrocidades fueron plenamente compartidos; los actores criminales fueron reclutados en todos los sectores políticos. El campesino liberal no se limitaba simplemente a defenderse sino que respondía al horror con el horror. Con base en esta reciprocidad, Monseñor Guzmán concluye que el campesino no fue simplemente una víctima, sino también un victimario que había encontrado en sus propias condiciones de vida estímulos para actuar por cuenta propia, más allá de las consignas o de las órdenes inmediatas de sus jefes políticos. La violencia, pues, se encuentra profundamente arraigada en las condiciones de vida del campesino $\mathrm{y}$, por consiguiente, no es simplemente una violencia instrumental de carácter ofensivo o defensivo.

El libro logra superar una lectura del conflicto inclinada hacia un partido al dar cuenta, de manera indistinta, de la literatura producida por ambos partidos. En el capítulo I, por ejemplo, para describir el preámbulo de La Violencia, que va de 1946 a 1949, apela de manera significativa a una literatura de carácter conservador, como es el caso de los libros El materialismo contra la dignidad del hombre, de Roberto Urdaneta Arbeláez - político conservador que reemplazó a Laureano Gómez en la presidencia-, La batalla contra el comunismo en Colombia, de José María Nieto Rojas -el gran defensor de Rojas Pinilla en nombre de los conservadores ospinistas - , y De la revolución al nuevo orden, de Rafael Azula Barrera - conservador boyacense de orientación laureanista -, entre otros. La literatura producida por cada uno de los bandos es utilizada para ponerla a dialogar con su contraparte y sirve para contrastar las diferentes versiones de los hechos.

La Violencia en Colombia da un paso adelante con respecto a la lógica de las recriminaciones y de las responsabilidades mutuas entre los partidos liberal y conservador, y establece un juicio terminante en el que "todos somos culpables". Esta afirmación se podría interpretar como una versión eufemística de la impunidad establecida por el Frente Nacional y, por consiguiente, como una forma de hacer compatible sus denuncias con el ambiente de concordia establecido por este pacto político. No obstante, también se podría interpretar como una manera de separar el juicio de responsabilidades de la exploración propiamente sociológica del conflicto. Sin negar que las investigaciones que llevan a cabo las ciencias sociales tienen implicaciones éticas y políticas, habría que reconocer que el estudio profundo de un problema cualquiera -individual o colectivo - supone, en cierta medida, la neutralización del juicio de responsabilidades o de las valoraciones éticas. Esta sería entonces la opción escogida por el texto.

Si bien este libro supera las recriminaciones mutuas entre los partidos, también incluye un enjuiciamiento profundo en otra dirección. Los verdaderos protagonistas de La Violencia no son los partidos liberal y conservador, sino dos actores sociales definidos como las oligarquías y el pueblo. Como documento de denuncia, el libro es en una buena medida un enjuiciamiento de la responsabilidad de las oligarquías, que "no estuvieron a la altura de su condición como clase dirigente". A lo largo de sus páginas aparece, en diversos momentos, una serie de preguntas dirigidas a los principales líderes nacionales, que buscan indagar por su sentido de responsabilidad $\mathrm{y}$ acusarlos de no haberse dado cuenta en su debido momento de las graves consecuencias que su enfrentamiento podía tener en las masas campesinas. Según Monseñor Guzmán, cuando se dieron cuenta de que habían desatado de manera indolente un conflicto de inmensas proporciones, ya no pudieron hacer nada. El campesino - nos dice Monseñor - fue arrastrado a la violencia sin que los condotieros de turno se percataran de cuán peligroso es jugar en Colombia a la revolucióncon labriegos (Guzmán, Fals y Umaña, 1980, p. 43).

Elenjuiciamiento delas oligarquías se desdobla a su vez, en términos académicos, en una investigación sobre el campesino colombiano de la época que, dejado a su libre juego, es capaz de llegar a grandes extremos. El doble carácter del 
libro como documento político y académico al mismo tiempo nos permite hacer comprensible estas oscilaciones.

\section{La investigación sobre el campesino colombiano}

Una de las características más importantes del Frente Nacional es que se trata de un acuerdo por lo alto entre las grandes líderes de los partidos políticos, a espaldas de las grandes masas del pueblo colombiano. Las élites políticas, después de las experiencias de las décadas anteriores, manifiestan un inmenso temor frente a la posibilidad de que esas "masas peligrosas" irrumpan en la escena pública y, por este motivo, diseñan un pacto oligárquico en el que las grandes directrices se encuentran en manos de los directorios políticos, con exclusión de las llamadas "bases" de los partidos a las que solo se apela para ratificar las decisiones ya tomadas. Tras el pánico a una nueva irrupción de la barbarie se encuentra el temor a la afirmación autónoma del pueblo por fuera de sus dirigentes.

La irrupción de las masas en el escenario político se había llevado a cabo debido al discurso de Gaitán en los años cuarenta, a la acción espontánea de las masas campesinas durante La Violencia de los años cincuenta y a través de la convocatoria del pueblo que llevó a cabo con algún éxito el incipiente populismo de Rojas Pinilla. Buena parte del interés en juzgar al General provenía del pánico que existía respecto a la posibilidad de que, a su regreso al país - tras su salida el 10 de mayo de 1957- pudiera movilizar de nuevo los sectores populares. Para hacer frente a este temor, el Frente Nacional no solo significaba la elución de la responsabilidad de los dirigentes políticos, sino también el desconocimiento $\mathrm{y}$ la estigmatización de la actividad de las masas campesinas pero, sobre todo, el desconocimiento de estas mediante el silencio. El "temor al pueblo" era una característica fundamental del nuevo pacto, aspecto contra el cual se vuelca La Violencia en Colombia, de Monseñor Guzmán, Fals y Umaña (1980), al convertir las condiciones del campesino que hizo la violencia en objeto de investigación por parte de las ciencias sociales.
En la época en que el libro fue escrito no existía, o al menos en Colombia no se había difundido, la metodología de las historias de vida. Por ello resulta novedoso el capítulo VI, que presenta un esbozo de una forma inédita de hacer sociología a través de la presentación de las semblanzas: de Eliseo Velásquez en los Llanos Orientales, Leopoldo García en el Tolima, Teodoro Tacumá en el Huila, Teófilo Rojas en la zona cafetera, Rafael Rangel en Santander y Juan de Jesús Franco en Antioquia. A estas presentaciones se agregan otras referencias a los actores concretos de La Violencia que aparecen en otros lugares del texto. La idea, en últimas, consiste en mostrar que los campesinos colombianos protagonistas del fenómeno eran "personas perfectamente integradas a la estructura social prebélica" y que, debido una serie de factores, terminaron comprometidos en un conflicto de inmensas proporciones. No se trataba pues de "monstruos" o de "criminales constitucionales", sino de personas confrontadas con una serie de circunstancias históricas concretas.

En este sentido, La Violencia en Colombia se podría considerar como una gran investigación sobre la idiosincrasia del campesino colombiano Este libro va en la misma línea que otro clásico de las ciencias sociales de aquella época: Campesinos de los Andes, de Orlando Fals Borda, publicado en 1961. Este segundolibro se preocupa por entender sociológicamente al campesino colombiano de la época que, independientemente de su color político, hace parte de una identidad llamada pueblo. Por ello, es pertinente preguntarse en qué trabaja, cuáles son sus condiciones de vida, de qué es capaz, cuál es el tipo de relación que establece con los dirigentes políticos y hasta qué punto tiene la posibilidad de desarrollar una conciencia autónoma de su situación. Estas son las peguntas de investigación más importantes que se encuentran detrás de todas sus descripciones empíricas y que se responden a partir de lo que fue su participación en la llamada Violencia.

En el marco de esta investigación sobre el campesino colombiano se inscribe la interpretación que el libro propone sobre el fenómeno de La Violencia que no ha sido 
suficientemente tenida en cuenta en los estudios posteriores. La mayor parte de las veces, cuando se hace referencia a la interpretación que aparece en este libro, se citan las aclaraciones explícitas que el texto elabora en alguno de sus apartes, como es el caso, por ejemplo, del famoso capítulo XIII del primer volumen, en el cual se despliega todo un aparataje conceptual de origen funcionalista para interpretar el fenómeno; o del capítulo VI de la tercera parte del tomo II, llamado "Etiología de La Violencia" en el que, al seguir un esquema bastante convencional de la causalidad, se habla de más de cincuenta causas, que son presentadas incluso en un cuadro sinóptico. Sin embargo, no se tiene en cuenta que detrás de la descripción de los hechos existe una interpretación implícita, que puede ir mucho más allá de lo que explícitamente se formula.

Monseñor Guzmán presenta a La Violencia como un proceso que tiene varios actos, como una obra de teatro o de ópera. El primer acto es una especie de obertura, que va entre 1946 y 1949, durante el cual se enfrentan dos bandos en el escenario político nacional, encarnados por el Senado y la Cámara de Representantes. Los principales protagonistas son los grandes líderes nacionales de origen oligárquico, que se disputan sobre si deben apoyar al gobierno conservador o al intento de derrocarlo, en el marco de un clima generalizado de "engaño, conspiración" e intolerancia (Guzmán, Fals y Umaña, 1980, p. 14), altamente determinado por la expectativa de las elecciones para cuerpos colegiados o para Presidente de la República. Uno de los bandos, con base en la utilización de recursos oficiales como la policía, quiere exterminar al otro bando, al que no le queda otro recurso que la defensa ante la agresión sufrida.

Los bandos así enfrentados no son conscientes en ningún momento de que lo que ocurre en el escenarionacional de la política tiene repercusiones y "efectos inesperados" en los niveles locales como el departamento, el municipio o la vereda rural, de forma que se produce entonces un desplazamiento del clima de violencia de las oligarquías al pueblo, el cual comienza a reproducir por su propia iniciativa lo que sucede en las grandes esferas. La Violencia tienesu origen en "las cámaras legislativas y en los despachos oficiales de Bogotá", pero desciende a través de diversos canales, "de lo nacional a lo regional, de lo regional a lo comunal, de lo comunal a lo vecinal, de lo vecinal a lo familiar y de lo familiar a lo diadico" (Guzmán, Fals y Umaña, 1980, p. 405) hasta causar el enfrentamiento propiamente dicho. Las actitudes y las consignas se trasladan de esta manera de un espacio a otro y modifican "la estructura de los valores del pueblo colombiano"; el proceso se da igualmente en sentido contrario.

El conflicto se arraiga en las condiciones de vida del campesino y toma vida propia. La lucha que se desarrolla en el plano nacional, entre sectores de la oligarquía, se convierte en una "lucha fratricida entre campesinos", una "mutua vendetta inmisericorde" que, instalada en la "entraña del pueblo", "se alimenta de todas las formas del resentimiento, del odio, de la crueldad y del sadismo (Guzmán, Fals y Umaña, 1980, cap. III). Se puede deducir, según lo anterior, que la violencia no es simplemente la acción instrumental de las clases dominantes que supieron aprovecharse de las clases subalternas para movilizarlas, engañarlas y utilizarlas en favor de sus intereses hasta llevarlas al sacrificio y a la muerte; el campesino no es un simple agente pasivo, sino un actor social que asume la violencia como un proyecto propio, inscrito en sus propias condiciones de vida: el campesino es, al mismo tiempo, víctima y victimario. La violencia se convierte en la forma de afirmación autónoma de un pueblo.

El modelo de interpretación que propone el libro La Violencia en Colombia, al transformar la oposición liberal conservadora en una oposición entre las oligarquías y el pueblo, se inscribe en un imaginario político propio del populismo de los años cuarenta, pero impregnado de los valores del catolicismo, como la piedad, la misericordia y la caridad. La Violencia en Colombia es una nueva versión de la movilización populista iniciada por Jorge Eliécer Gaitán en los años cuarenta, con la diferencia de que el pueblo ya no es la masa urbana de las ciudades, sino la población que habita los campos. En La Violencia ya no hay líderes, sino un pueblo autónomo que 
actúa por sí mismo, y que ha sido dejado a su propia suerte. El gaitanismo, como fenómeno populista, tenía un importante componente ideático y representacional en el plano de lo imaginario, representado por un discurso político que actuaba como inhibidor del paso al acto, es decir, como freno de la violencia. La Violencia corresponde, por el contrario, al orden de lo real, de lo que no puede ser verbalizado ni simbolizado a través de un discurso político o de un relato con sentido. La gran "tragedia del pueblo colombiano" consistiría, pues, según la interpretación de Germán Guzmán, en el hecho de que la autonomía del pueblo se traduce en violencia. Ante esta situación, la única posibilidad de recuperación es un sentimiento cristiano de piedad y de conmiseración.

\section{Los responsables de la trasgresión}

El libro La Violencia en Colombia constituye, como lo hemos demostrado a lo largo de este artículo, una trasgresión a los presupuestos básicos del Frente Nacional. Sin embargo, la responsabilidad de este hecho no proviene de las propias élites políticas, como ocurrió en el enjuiciamiento que se llevó a cabo en esta época durante el juicio al General Rojas Pinilla en el Congreso, sino del mundo académico. Las ciencias sociales en Colombia estaban recién fundadas y la Sociología, en particular, había logrado institucionalizarse con la creación de la Facultad de Sociología de la Universidad Nacional de Colombia en 1959, por parte del sociólogo Orlando Fals Borda con el apoyo del cura Camilo Torres, Roberto Pineda, Andrew Pearse, Virginia Gutiérrez de Pineda y Tomás Ducay, entre otros.

La Facultad de Sociología estaba ampliamente comprometida en llevar a cabo investigaciones concretas sobrelarealidad nacional, investigaciones que fueran más allá de la "repetición libresca y especulativa" de autores y escuelas. Bajo este objetivo ya había producido varias obras importantes en los años anteriores, incluso monografías sobre La Violencia, la primera a cargo de Roberto Pineda, llamada El impacto de la Violencia en el Tolima: el caso de El Líbano y la segunda a cargo de Camilo Torres, que tuvo por título La Violencia y los cambios socioculturales en áreas rurales colombianas. El libro La Violencia en Colombia corresponde a la monografía número doce de la serie mencionada.

La iniciativa de publicar el libro provino precisamente de los profesores de la Facultad de Sociología, quienes a comienzos de 1961 hicieron un viaje hasta El Líbano (Tolima) para proponerle a Monseñor Guzmán la publicación de un libro que recogiera la información de que disponía como resultado de su participación en la Comisión Investigadora de las Causas Actuales de la Violencia, convocada por iniciativa de la Junta Militar de Gobierno (1957-1958), con el respaldo de Alberto Lleras Camargo, presidente electo para el periodo 1958-1962. Este último, incluso, ya le había propuesto a Guzmán que escribiera un libro, para aprovechar sus conocimientos sobre el tema; el Presidente colaboró en la obtención de la dispensa eclesiástica para ser el autor de un documento público sobre un asunto tan delicado. Más adelante, recibió en Palacio a los autores del libro y muy probablemente discutió con ellos su contenido; ellos incluso agradecen de una manera muy sincera su colaboración (Guzmán, Fals y Umaña, 1980, p. 12).

La huella de la participación de los profesores de la Facultad de Sociología de la Universidad Nacional se encuentra presente a lo largo del texto. El prólogo puede ser considerado como una especie de "manifiesto sociológico" que da cuenta del proyecto intelectual de la naciente sociología en Colombia. El capítulo XIII del tomo I es considerado por Fals Borda como la expresión del punto de vista de los profesores de esta unidad académica. La influencia del funcionalismo norteamericano, corriente dominante en ese momento en la sociología, aparece claramente a lo largo del texto. La publicación de este libro es probablemente la primera vez que un sector académico irrumpe en el escenario nacional para llevar a cabo una intervención política, pero sin renunciar a sus propios criterios. 


\section{Referencias}

Azula Barrera, R. (1956). De la Revolución al nuevo orden: proceso y drama de un pueblo. Bogotá: Editorial Kelly.

El discurso inaugural. (1958, 8 de agosto). La República, editorial.

El increíble caso del señor Rojas Pinilla. (1959, 6 de febrero). El Crisol, editorial.

El proceso de las recriminaciones. (1958, 31 de enero). El Crisol, editorial.

Guzmán Campos, G. (1962). La Violencia en Colombia. Estudio de un proceso social. Tomo I. Bogotá: Ediciones Tercer Mundo.

Guzmán, G.; Fals, O.; Umaña, E. (1980). La Violencia en Colombia. Estudio de un proceso social. Tomo II. Bogotá: Carlos Valencia Editores.

Merton, R. (1995). Teoría y estructura sociales. México: Fondo de Cultura Económica.

Nieto Rojas, J. M. (1956). La batalla contra el comunismo en Colombia. Bogotá: Empresa Nacional de Comunicaciones.

No se trata de revivir odios. (1959, 7 de febrero). El Tiempo, editorial.

Ortiz, C. (1987). Estado y subversión en Colombia. La Violencia en el Quindio años 50. Bogotá: Cider; Uniandes; Cerec.

Por qué segunda República. (1958, 1 de septiembre). El Tiempo, editorial.

Se busca dividir a los partidos y socavar el Frente Nacional. Dijo el Doctor Lleras Restrepo sobre las acusaciones de Valois Arce. (1959, 8 de febrero). El Tiempo.

Senado De La República, Comisión Instructora. (1960). El Proceso contra Gustavo Rojas Pinilla ante el Congreso de Colombia. Bogotá: Imprenta Nacional, tomos I, II y III.
Una política triunfante (1959, 2 de enero). El Tiempo, editorial.

Un mar de acusaciones. (1959, 1 febrero). La República, editorial.

Valencia, A. (2012). El proceso político contra el General Gustavo Rojas Pinilla en el Congreso de Colombia (1958-1959). Tesis de doctorado en sociología Ecoles des Hautes Études en Sciences Sociales, París, (abril de 2012 envío de publicación).

Valencia, A. (2012). Memoria y violencia. A los 50 años de "La Violencia en Colombia" de Monseñor Guzmán (et al). Revista sociedad y economía, 23(2).

Zalamea, J. (1957). Las jornadas de mayo. Bogotá: Editorial Antares.

\section{Referencias consultadas}

Blandón Berrio, F. (1996). Lo que el cielo no perdona. Bogotá: Editorial Planeta.

Camacho, Á. y Segura, N. (2000). En los cuarenta años de la sociología colombiana. En F. Leal Buitrago y G. Rey. (eds.). Discurso y razón. Una historia de las ciencias sociales en Colombia. Bogotá: Tercer Mundo Editores.

Fals Borda, O. (1961). Campesinos de los Andes: estudio sociológico de Saucío. Bogotá: Universidad Nacional de Colombia.

Franco Isaza, E. (1994). Las Guerrillas del Llano. Bogotá: Editorial Planeta.

Guerrero Barón, J. (1991). Los años del olvido. Boyacá y los orígenes de la Violencia. Bogotá: Tercer Mundo Editores; Instituto de Estudios Políticos y Relaciones Internacionales (IEPRI).

Hilarión, A. (s. f.). Balas de la ley. Bogotá: Editorial Santafé. 
Manrique, R. (1955). Los días del terror. Bogotá: Editorial ABC.

Oquist, P. (1978). Violencia, conflicto y política en Colombia. Bogotá: Biblioteca Banco Popular.

Ortiz, C. (1994). Historiografía de La Violencia. En Tovar Zambrano, B. La historia al final del milenio. Ensayos de historiografía colombiana y latinoamericana. Bogotá: Universidad Nacional de Colombia.

Pécaut, D. (1987). L'Ordre et la Violence. Évolution socio-politique de la Colombie entre 1930 et 1953. Paris: Éditions de l'École des Hautes Études en Sciences Sociales.

Pécaut, D. (2001). Orden y violencia. Evolución socio-política de Colombia entre 1930 y 1953. Bogotá: Editorial Norma.

Sánchez, G. (1989). La Violencia: de Rojas al Frente Nacional. En Tirado Mejía, Á. et al, (comp.).
Nueva Historia de Colombia (tomo II, 153178). Bogotá: Editorial Planeta.

Sánchez, G. y Peñaranda, R. (1986). Pasado y presente de La Violencia en Colombia. Bogotá: Cerec.

Sierra Ochoa, G. (1954). Las guerrillas de los Llanos Orientales. Manizales: Imprenta Departamental.

Testis, F. (1955). De Caín a Pilatos o lo que el cielo no perdonó. Houston: Universidad de Texas.

Testis, F. (1953). El basilisco en acción o los crímenes del Bandolerismo. Medellín: Tipografía Olympia.

Urdaneta Arbeláez, R. (1962). El materialismo contra la dignidad del hombre. Su impacto en la vida colombiana. Bogotá: Editorial Lucros. 